ARTICLE

\title{
Unusual layer-by-layer growth of epitaxial oxide islands during $\mathrm{Cu}$ oxidation
}

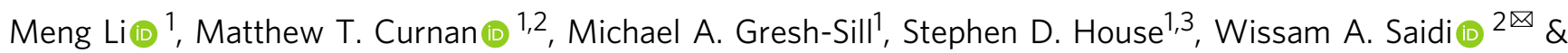
Judith C. Yang $1,3,4 凶$

Elucidating metal oxide growth mechanisms is essential for precisely designing and fabricating nanostructured oxides with broad applications in energy and electronics. However, current epitaxial oxide growth methods are based on macroscopic empirical knowledge, lacking fundamental guidance at the nanoscale. Using correlated in situ environmental transmission electron microscopy, statistically-validated quantitative analysis, and density functional theory calculations, we show epitaxial $\mathrm{Cu}_{2} \mathrm{O}$ nano-island growth on $\mathrm{Cu}$ is layer-bylayer along $\mathrm{Cu}_{2} \mathrm{O}(110)$ planes, regardless of substrate orientation, contradicting classical models that predict multi-layer growth parallel to substrate surfaces. Growth kinetics show cubic relationships with time, indicating individual oxide monolayers follow Frank-van der Merwe growth whereas oxide islands follow Stranski-Krastanov growth. Cu sources for island growth transition from step edges to bulk substrates during oxidation, contrasting with classical corrosion theories which assume subsurface sources predominate. Our results resolve alternative epitaxial island growth mechanisms, improving the understanding of oxidation dynamics critical for advanced manufacturing at the nanoscale.

\footnotetext{
${ }^{1}$ Department of Chemical and Petroleum Engineering, University of Pittsburgh, Pittsburgh, PA, USA. ${ }^{2}$ Department of Mechanical Engineering \& Materials Science,, University of Pittsburgh, Pittsburgh, PA, USA. ${ }^{3}$ Environmental TEM Catalysis Consortium (ECC), University of Pittsburgh, Pittsburgh, PA, USA.

${ }^{4}$ Department of Physics and Astronomy, University of Pittsburgh, Pittsburgh, PA, USA. ${ }^{凶}$ email: alsaidi@pitt.edu; judyyang@pitt.edu
} 
dvanced manufacturing of nanostructured metal oxides (MOs) is essential for myriad applications including energy, electronics, sensors, photocatalysts, bio-medicine, and recently for quantum computing ${ }^{1-12}$. Thus, precise, scalable synthesis and processing of nanostructured MOs are in much demand $^{13}$. Microfabrication methods, such as thermal oxidation, reactive sputtering, and atomic layer deposition, are promising approaches for preparing large batches of epitaxially nanostructured $\mathrm{MO}^{14,15}$. However, current nano-oxide fabrication methods, for which oxidation is a vital step, are empirically based. To better predict and control the shape of nanostructured MOs, a fundamental understanding of the oxide nanocrystal growth process is essential. Established oxidation theories of Wagner ${ }^{16}$ and Cabrera-Mott ${ }^{17}$ treat the oxidation process exclusively from a macroscopic viewpoint assuming simplified, continuous uniform layers. While these models have been successful in guiding fabrication of amorphous oxide films-such as $\mathrm{SiO}_{2}$ - and corrosion mitigation, they have little predictive power for describing nanostructured MOs due to their lack of atomic crystalline considerations. This shortcoming greatly hinders the industrial manufacturing of nanostructured MOs.

Borrowing from thin-film growth theories, $\mathrm{MO}$ nanocrystals that attach to a metal substrate epitaxially during the growth of three-dimensional (3D) oxide islands are explained using the Stranski-Krastanov (layer-plus-island) growth mode ${ }^{14,18}$. However, this model is defined from an interfacial energy viewpoint, leaving the kinetic process of how these nanostructures form uncertain. One well-accepted kinetic process is the multilayer growth mechanism, which explains the formation of $3 \mathrm{D}$ islands as the simultaneous growth of multiple layers stacked parallel to the substrate surface, forming "wedding cake"-shaped islands ${ }^{19-21}$. For example, islands on (100) substrates form by the concurrent growth of multiple stacked layers along the (100) plane ${ }^{21}$. However, 3D islands with faceted crystal surfaces are also widely observed, such as pyramidal $\mathrm{Ge}$ and $\mathrm{Si}$ islands in quantum dots ${ }^{22-24}$, nano-wedgeshaped $\mathrm{Fe}$ islands ${ }^{25}$, and $3 \mathrm{D} \mathrm{Cu}_{2} \mathrm{O}$ islands on $\mathrm{Cu}^{26-29}$. While these faceted crystal surfaces are at variance with the multilayer growth mechanism, it remains unclear whether the deviations are due to the early or the later stages of the island growth. The lack of direct observation of the growth dynamics at the atomic scale has hindered establishing a fundamental mechanistic explanation for the growth of the 3D epitaxial islands. Recent developments in in situ environmental transmission electron microscopy (ETEM)-with which material systems can be examined under relevant reaction conditions-offer a solution to this problem, enabling the direct observation of growth dynamics $4,30,31$. However, the results heretofore have been qualitative at best. Extracting statistically meaningful quantitative atomic-scale growth kinetics from the in situ movies, which is critical for understanding atomic-scale growth mechanisms, has become the new challenge.

Herein we perform in situ ETEM oxidation experiments on copper-the most well-studied model material for oxidation that forms epitaxial oxide islands-to provide direct, atomic-scale observations of the growth dynamics of 3D epitaxial oxide islands during oxidation. Quantitative atomic-scale information was extracted using advanced image analysis techniques. By correlating the experimental observations and statistical validation of growth kinetics with density functional theory (DFT) modeling, we present an unusual epitaxial layer-by-layer growth mechanism for the oxide island along a preferred surface facet, unforeseen by previous crystal growth theories.

\section{Results}

Layer-by-layer $\mathrm{Cu}_{2} \mathrm{O}$ growth along $\mathrm{Cu}_{2} \mathrm{O}(110)$. $3 \mathrm{D} \mathrm{Cu}_{2} \mathrm{O}$ islands were formed by oxidizing single-crystalline $\mathrm{Cu}$ films inside the
ETEM at $300{ }^{\circ} \mathrm{C}$ under $0.3 \mathrm{~Pa} \mathrm{O}_{2}$. In agreement with previous studies ${ }^{32,33}$, these $\mathrm{Cu}_{2} \mathrm{O}$ islands share cube-on-cube epitaxy with the $\mathrm{Cu}$ substrate. The $\mathrm{Cu}_{2} \mathrm{O}$ islands on $\mathrm{Cu}(100)$ were reported to follow the Stranski-Krastanov (S-K) growth mode, in which a transition from 2D wetting layers to $3 \mathrm{D}$ islands was observed beyond a critical thickness ${ }^{34}$. According to previous models ${ }^{33,35}$, the oxide is expected to grow along the $\mathrm{Cu}$ surface, such as along $\mathrm{Cu}_{2} \mathrm{O}(100)$ on $\mathrm{Cu}(100)$. However, as shown in Movie $\mathrm{S} 1$ and Fig. 1, we found that the $\mathrm{Cu}_{2} \mathrm{O}$ islands on both $\mathrm{Cu}(100)$ and (110) surfaces (Supplementary Note 1, Supplementary Figs. 2-5, and Supplementary Movies 2-4) grew along the $\mathrm{Cu}_{2} \mathrm{O}(110)$ planes in a layer-by-layer adatom growth mode. This is usually observed in Frank-van der Merwe (F-M) growth where the interface mismatch energy is negligible, leading to the formation of a thin-film, instead of islands, along the substrate surface. Our study shows that although the resultant $\mathrm{Cu}_{2} \mathrm{O}$ islands follow the $\mathrm{S}-\mathrm{K}$ growth mode, the formation of each $3 \mathrm{D}$ island follows a layer-by-layer growth along a certain plane that is not necessarily parallel to the substrate surface, contradicting classical predictions.

$\mathrm{Cu}_{2} \mathrm{O}$ monolayer growth kinetics. To better understand the growth kinetics of each monolayer, we performed quantitative analysis on the boxed area in Fig. 1d on the atomically aligned movie to measure the size evolution of each layer over time (Fig. 1f, Supplementary Note 3). As illustrated in Fig. 1e, each new layer is a $2 \mathrm{D}$ flake that grows in both planar directions. Although TEM images only provide 2D through-thickness projections of the growing new layer, given that the two directions are equivalent $\{110\}$ planes, the projected length evolution in one dimension can be used to estimate the growth in both directions. The nucleation sites of each $\mathrm{Cu}_{2} \mathrm{O}$ monolayer (Fig. $1 \mathrm{~g}$ and Supplementary Fig. S6) were randomly distributed on the previously grown layer, indicating identical nucleation energetic favorability across all sites. Despite that the layer edges typically proceeds in stairs (Fig. 1g), the total projected lengths $(l)$ all exhibited a similar smooth growth trend following a cube root relationship with time $(t): l^{3}=A t$ (referred to as cubic relationship for short hereafter, Fig. 1h, Supplementary Fig. 14, and Supplementary Note 3). As a result, the growth rate of the island size is quasi-linear along the [110] direction and cubic along [100] and [010] directions. Interestingly, typical oxide thickness curves found in bulk $\mathrm{Cu}$ oxidation experiments in this temperature range also follow cubic rates ${ }^{36}$, which were explained based on classical oxidation theory ${ }^{17}$ due to the formation and diffusion of cation vacancies through an oxide layer that fully covers the metal surface. However, this explanation does not apply to our sample, since the metal surface near the oxide island is still exposed. Instead, we argue that the cubic growth rate of each oxide monolayer could be explained using the diffusion-limited 2D growth kinetics of F-M thin-film growth ${ }^{19}$. In this growth mode, a full layer forms by coalescence of several single-monolayer-thick $2 \mathrm{D}$ flakes, where each flake grows with $l^{3} \sim t$ scaling ${ }^{37-39}$. The main difference with the thin-film F-M growth is that the observed growth of the oxide monolayer in our samples is due to the nucleation of a single "flake", rather than many flakes as in thinfilms. This difference is likely because the effective substrate for the growth of the oxide layer is relatively small compared to typical thin-film substrates. Presumably, as the MO islands grow in size, layer formation through the coalescence of more than one flake would occur. Hence, the observed $l^{3} \sim t$ growth kinetics of each monolayer indicates a diffusion-limited process, possibly due to surface diffusion of $\mathrm{Cu}$ and $\mathrm{O}$ atoms to form adatoms at the $\mathrm{Cu}_{2} \mathrm{O}$ monolayer edge.

The growth trajectories also exhibited coordinated increments and oscillations between multiple layers (Fig. 1g-i). To substantiate 


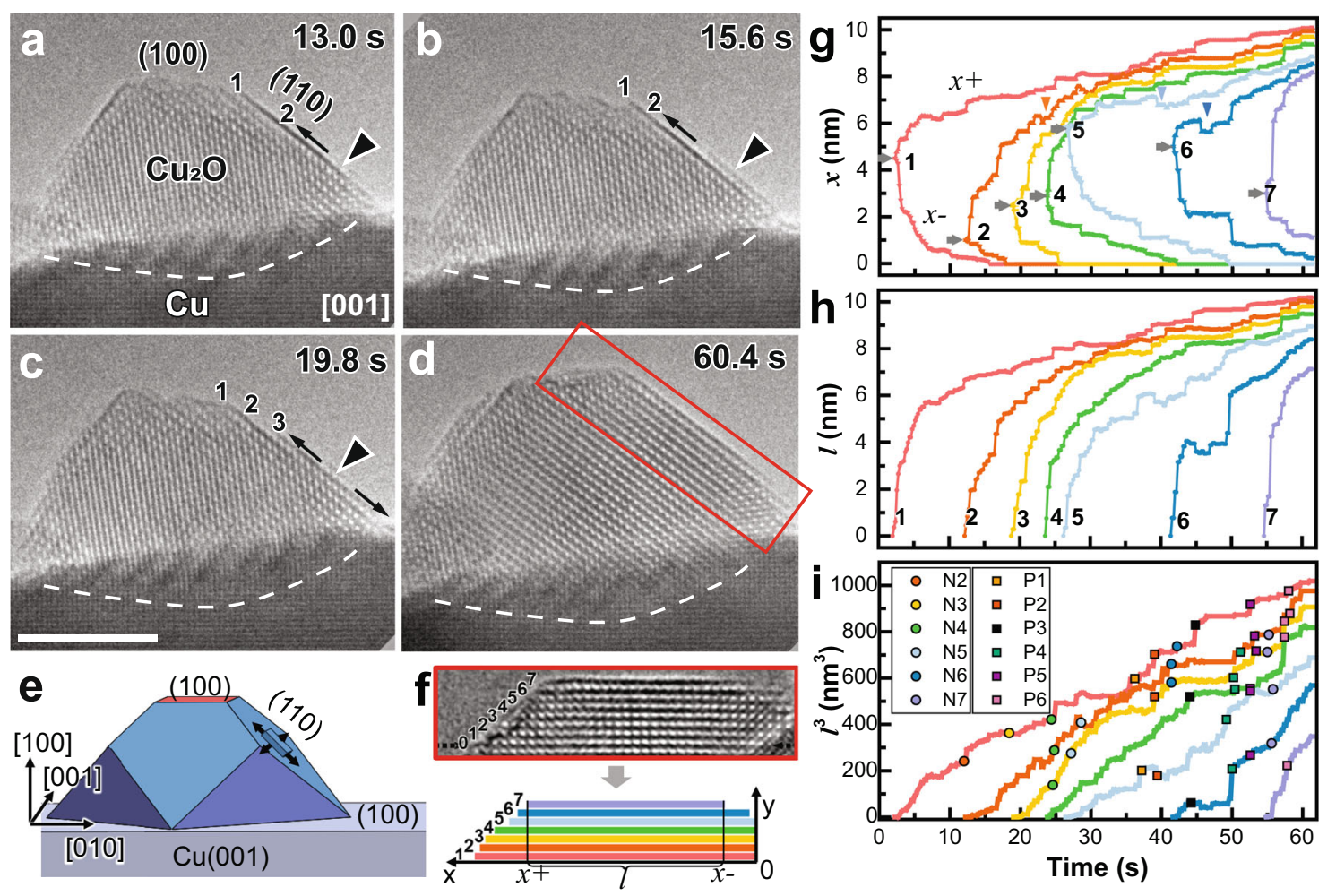

Fig. 1 Layer-by-layer growth of $\mathbf{C u}_{\mathbf{2}} \mathbf{O}$ island along $\mathbf{C u}_{\mathbf{2}} \mathbf{O}$ (110) during $\mathbf{C u ( 1 0 0 )}$ oxidation. a-c Snapshots from Supplementary Movie 1 showing adatom growth of the $2^{\text {nd }} \mathrm{Cu}_{2} \mathrm{O}$ new layer at $300^{\circ} \mathrm{C}$ and $p_{\mathrm{O} 2}=0.3 \mathrm{~Pa}$. The layer nucleation site (triangle) and growth direction (arrow) are indicated. Scale bar: $5 \mathrm{~nm}$. $\mathbf{d}$ The island top forms a flat $\mathrm{Cu}_{2} \mathrm{O}(100)$ plane over time. e Schematic 3D model of the $\mathrm{Cu}_{2} \mathrm{O}$ island with a growing new layer. $\mathbf{f}$ The boxed area from d, reoriented for growth trajectory measurement, with a corresponding schematic defining the measured data plotted in $\mathbf{g}$-i. $\mathbf{g}$ Growth trajectory coordinates of the left $(x+)$ and right $(x-)$ ends of each layer with time, namely when measuring from the right side of the image defined in $\mathbf{f}$. Nucleation sites on each layer, marked by gray arrows, indicate a random site distribution. These two ends show stepwise growth with oscillations marked by triangles of matching colors. $\mathbf{h}$ The projected length $(I)$ of each layer shows a similar trend with smoother curves. $\mathbf{i}$ Statistically defined breakpoints in growth rates indicate nucleation events $(N)$ and interlayer atom diffusion events $(P)$.

these sudden changes, a multivariate time-series statistical analysis ${ }^{40}$ was performed ( $l^{3}$ vs. $t$ ) to evaluate when breaks in otherwise continuous growth occur ${ }^{37,38,41}$. The statistically defined structural breaks ${ }^{40}$, shown in Fig. $1 \mathrm{i}$ and Supplementary Note 4, are attributed to two types of events, namely the nucleation of new layers (N2-N7) and concerted diffusion events (P1-P6) describing the simultaneous change of growth rates among several layers. Nucleation events generally led to a growth rate decrease in previously grown layers, indicating that $\mathrm{Cu}$ and $\mathrm{O}$ attachment to the nucleating new layer is preferred over attachment to previous layers. This is likely caused by the Ehrlich-Schwöbel effect, in which downward diffusion across a surface step is prohibited due to an extra energy barrier ${ }^{42-44}$. Concerted diffusion events generally showed sudden decreases in the growth rates of new layers and increases in those of previous layers. This indicates a cross-layer diffusion of $\mathrm{Cu} / \mathrm{O}$ sourced from the new $\mathrm{Cu}_{2} \mathrm{O}$ monolayer to feed the growth of former layers, which corresponds to adjustment of the top of the $\mathrm{Cu}_{2} \mathrm{O}$ island from an initially zigzagged surface to a flat $\mathrm{Cu}_{2} \mathrm{O}(100)$ facet (Supplementary Figs. 7-8). Hence, both the oxide monolayer growth trend and variations in monolayer growth indicate a diffusion-limited layer-by-layer growth process resembling the $\mathrm{F}-\mathrm{M}$ thin-film growth mode, although the overall oxide island follows the S-K mode.

DFT calculations on $\mathrm{Cu}_{2} \mathrm{O}$ monolayer growth mechanism. To better understand why the oxide grows along the $\mathrm{Cu}_{2} \mathrm{O}(110)$ plane in disagreement with classical theories, DFT calculations were performed to study the earlier-stage atom-by-atom oxide growth events. Gas-solid interfacial energies $(\gamma)$ were calculated for the (100) and (110) $\mathrm{Cu}_{2} \mathrm{O}$ surface planes that are predominantly observed in our experiments. As shown in Fig. 2a and detailed in Supplementary Note $5, \mathrm{Cu}_{\mathrm{x}} \mathrm{O}_{\mathrm{y}}$ surface units were sequentially added to these planes to simulate layer growth. For flat $\mathrm{Cu}_{2} \mathrm{O}$ surfaces (column $i$ in Fig. 2a), Cu-O terminated $\mathrm{Cu}_{2} \mathrm{O}(110)$ had the lowest $\gamma$. Upon adding $\mathrm{Cu}_{\mathrm{x}} \mathrm{O}_{\mathrm{y}}$ surface units, $\mathrm{Cu}_{2} \mathrm{O}(110)$ surfaces with exposed $\mathrm{Cu}-\mathrm{O}$ layers invariably had the lowest $\gamma$. These surfaces include structures $i$ and $i i$ for $\mathrm{Cu}-\mathrm{O}$ terminated $\mathrm{Cu}_{2} \mathrm{O}(110)$ and structure $i i$ for $\mathrm{Cu}$-terminated $\mathrm{Cu}_{2} \mathrm{O}(110)$, and their favorability is attributable to their terminal, ionically bonded $\mathrm{O}-\mathrm{Cu}-\mathrm{O}$ chains (Supplementary Figs. 21-23). In contrast, O-terminated $\mathrm{Cu}_{2} \mathrm{O}(100)$ had the highest $\gamma$, regardless of the number of $\mathrm{Cu}_{\mathrm{x}} \mathrm{O}_{\mathrm{y}}$ surface units added to it. Such instability coincides with the undercoordination of exposed $\mathrm{O}$ atoms (Supplementary Fig. 20). Since $\mathrm{Cu}_{2} \mathrm{O}(100)$ structures must produce less-stable $\mathrm{O}$ terminations during its growth, oxide growth along $\mathrm{Cu}_{2} \mathrm{O}(110)$ is preferable to $\mathrm{Cu}_{2} \mathrm{O}(100)$. Simulated adatom adsorption events forming $\mathrm{Cu}_{\mathrm{x}} \mathrm{O}_{\mathrm{y}}$ surface unit $i$ (hollow data points in Fig. 2a and Supplementary Note 6) further support this conclusion. Therefore, $\gamma$ trend comparisons show that $\mathrm{Cu}_{2} \mathrm{O}(110)$ forms thermodynamically more favorable flat surfaces, grown $\mathrm{Cu}_{2} \mathrm{O}$ monolayers, and single adatom interfaces than $\mathrm{Cu}_{2} \mathrm{O}(100)$, in agreement with the experimental results.

Nudged elastic band simulations of the diffusion events along the oxide island surface further verified the experimentally observed layer-by-layer growth kinetics along the $\mathrm{Cu}_{2} \mathrm{O}(110)$ plane (Supplementary Note 7 ). Figure $2 \mathrm{~b}$ compares the preferred 

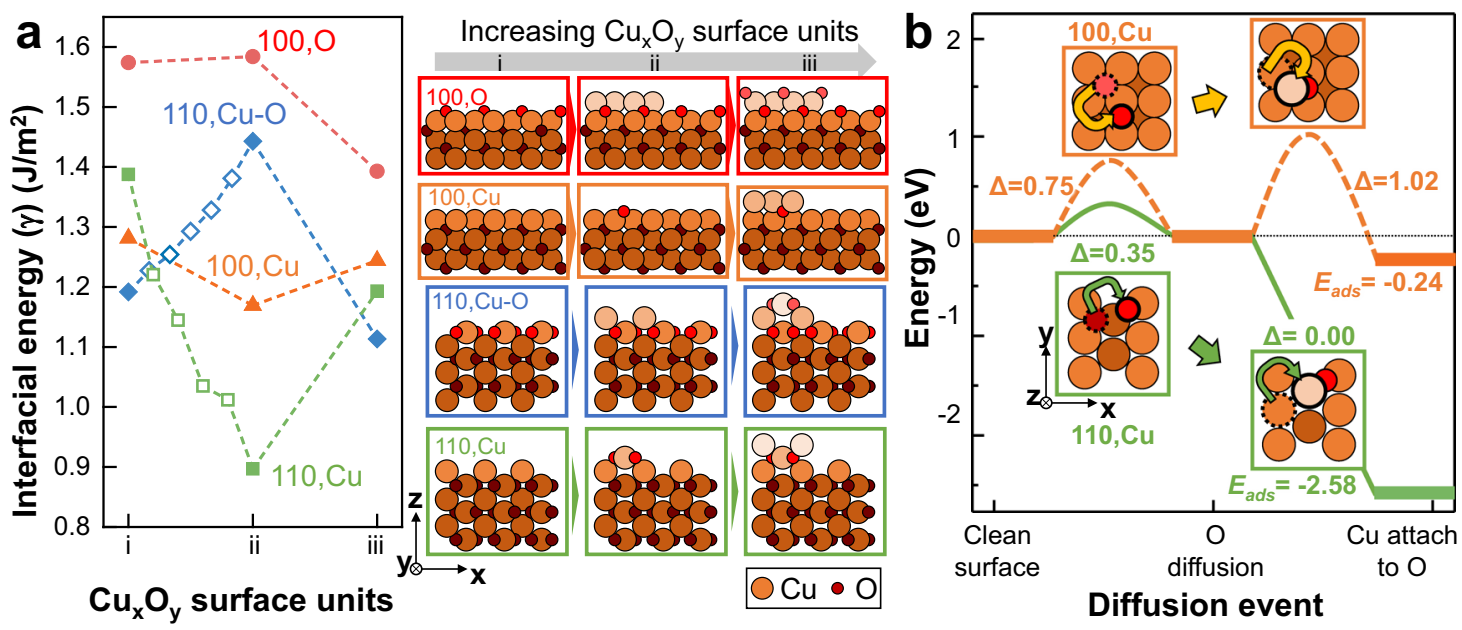

Fig. 2 DFT-calculated interfacial energies and diffusion energies for $\mathbf{C u}_{\mathbf{2}} \mathbf{O}$ (110) and (100) surfaces. a Most favorable structure $\gamma$ during $\mathrm{Cu}_{2} \mathrm{O}$ monolayer growth for $\mathrm{Cu}_{2} \mathrm{O}(110)$ with $\mathrm{Cu}$ (green) and $\mathrm{Cu}-\mathrm{O}$ (blue) terminations, and $\mathrm{Cu}_{2} \mathrm{O}(100)$ with $\mathrm{Cu}$ (orange) and $\mathrm{O}$ (red) terminations. The corresponding atomic structures are shown to the right of the plot, with matching border colors. Hollow data points between $i$-ii show adatom adsorption events forming the first $\mathrm{Cu}_{x} \mathrm{O}_{\mathrm{y}}$ surface unit. $\mathbf{b}$ Most-favorable $\mathrm{Cu}$ and $\mathrm{O}$ diffusion events on $\mathrm{Cu}_{2} \mathrm{O}$ surfaces linking diffusion barrier ( $\Delta$ ) and adsorption energy $\left(E_{a d s}\right)$. Insets with matching border colors show top-down views of the corresponding atomic structures. $\mathrm{Cu}$ and $\mathrm{O}$ atoms are colored in orange and red, respectively. Brighter/darker colors indicate a higher/lower z position.

diffusion mechanisms required to make an oxide layer on $\mathrm{Cu}$ terminated $\mathrm{Cu}_{2} \mathrm{O}(110)$ and $\mathrm{Cu}_{2} \mathrm{O}(100)$ surfaces. The most favorable rate-limiting diffusion process for forming $\mathrm{Cu}-\mathrm{O}$ layers on $\mathrm{Cu}$-terminated $\mathrm{Cu}_{2} \mathrm{O}(110)$ is single $\mathrm{O}$ diffusion with interchannel endpoints (diffusion barrier of $\Delta=0.35 \mathrm{eV}$ ), and the matching $\mathrm{Cu}$ diffusion process to place $\mathrm{Cu}$ on top of that $\mathrm{O}$ is barrierless with favorable adsorption energy $\left(E_{a d s}=-2.58 \mathrm{eV}\right)$. In comparison, the most favorable rate-limiting $\mathrm{O}$ diffusion process on a Cu-terminated $\mathrm{Cu}_{2} \mathrm{O}(100)$ surface is in-channel single $\mathrm{O}$ diffusion $(\Delta=0.75 \mathrm{eV})$. The matching $\mathrm{Cu}$ diffusion process places $\mathrm{Cu}$ on top of that $\mathrm{O}$, yielding a large barrier $(\Delta=1.02 \mathrm{eV})$ and less-favorable adsorption energy $\left(E_{a d s}=-0.24 \mathrm{eV}\right)$. The corresponding process for forming $\mathrm{Cu}$ layers on $\mathrm{Cu}-\mathrm{O}$ terminated $\mathrm{Cu}_{2} \mathrm{O}(110)$ is in-channel single $\mathrm{Cu}$ diffusion $(\Delta=0.42 \mathrm{eV}$, Supplementary Fig. 29). Rate-limiting step comparisons favor $\mathrm{Cu}_{2} \mathrm{O}(110)$ over $\mathrm{Cu}_{2} \mathrm{O}(100)$ not only across the initial and final states of the oxide layer formation process $(0.42 \mathrm{eV}$ vs. $1.02 \mathrm{eV})$ but also for each transient diffusing atom composition. Therefore, $\mathrm{Cu}$ and $\mathrm{O}$ prefer to diffuse to $\mathrm{Cu}_{2} \mathrm{O}(110)$ island growth fronts over $\mathrm{Cu}_{2} \mathrm{O}(100)$ fronts, further validating prior experimental outcomes.

$\mathrm{Cu}$ source for $\mathrm{Cu}_{2} \mathrm{O}$ island growth. The source of $\mathrm{Cu}$ during $\mathrm{Cu}_{2} \mathrm{O}$ growth also warranted investigation. Traditional oxidation theory ${ }^{17}$ argues that $\mathrm{Cu}$ is supplied from the metal||oxide interface through diffusion across the oxide, leading to an interface shift toward the metal side. However, as seen in Figs. 1 and Supplementary Fig. 6, the $\mathrm{Cu} \| \mathrm{Cu}_{2} \mathrm{O}$ interfaces predominantly remained unchanged during the oxidation process, particularly during the initial period of oxidation when there are few nucleated $\mathrm{Cu}_{2} \mathrm{O}$ islands. This indicates that there must be other sources for $\mathrm{Cu}$ instead of the substrate $\mathrm{Cu}$. A recent study found $\mathrm{Cu}_{2} \mathrm{O}$ island growth with gradual height decreases of the surrounding $\mathrm{Cu}$ surface steps ${ }^{45}$, inferring that $\mathrm{Cu}$ detaching from step edges might be the source. However, direct evidence for this claim has been lacking. Figure 3 and Supplementary Movie 5 show that during oxidation of $\mathrm{Cu}(100)$ facets with several one-atomic-layerhigh surface steps, these steps retreated when $\mathrm{Cu}_{2} \mathrm{O}$ grew, while the $\mathrm{Cu} \| \mathrm{Cu}_{2} \mathrm{O}$ interface remained unchanged. Due to the a

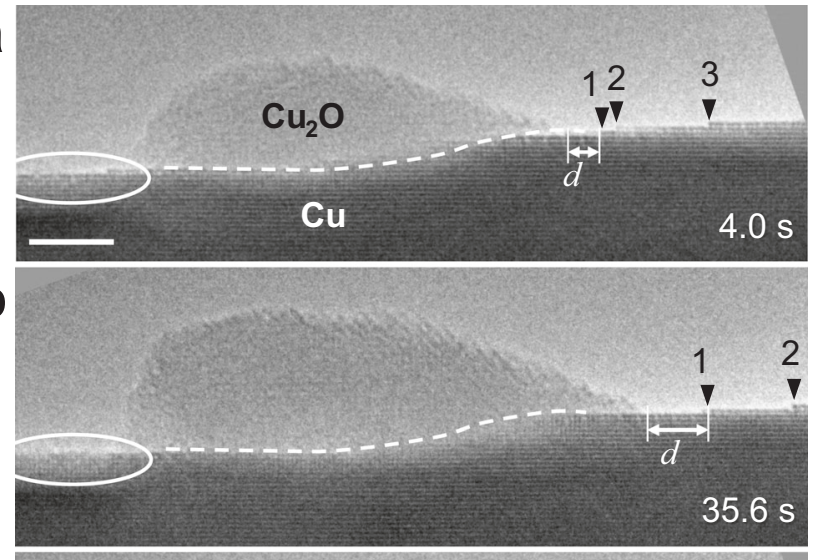

C

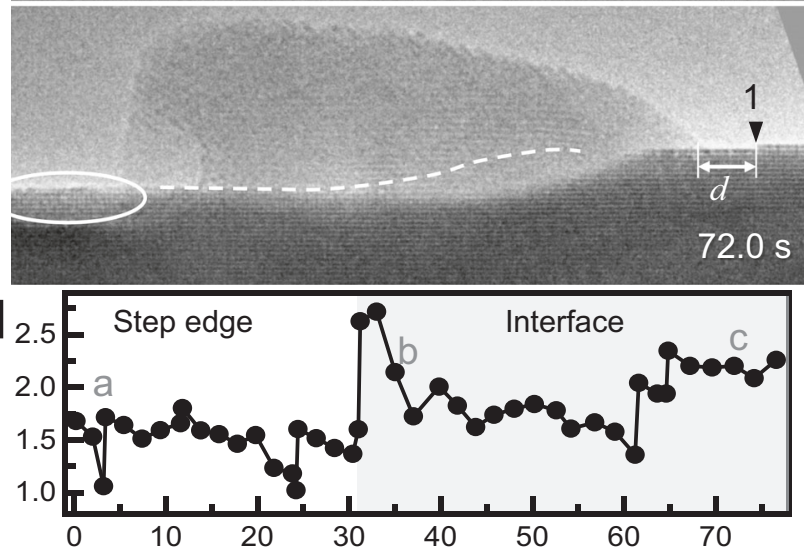

Fig. $3 \mathbf{C u}$ sources for $\mathbf{C u}_{\mathbf{2}} \mathbf{O}$ nano-island growth. $\mathbf{a}, \mathbf{b} \mathrm{Cu}_{2} \mathrm{O}$ grows while surface steps (1-3, marked by triangles) retreated and the $\mathrm{Cu} \| \mathrm{Cu}_{2} \mathrm{O}$ interface (dashed lines) remained unchanged. (Scale bar: $5 \mathrm{~nm}$ ). c When surface steps were far from the $\mathrm{Cu}_{2} \mathrm{O}$ island, $\mathrm{Cu}_{2} \mathrm{O}$ continued to grow and the $\mathrm{Cu} \| \mathrm{Cu}_{2} \mathrm{O}$ interface started to migrate towards $\mathrm{Cu}$. $\mathbf{d}$ A plot of the measured distance $(d)$ between the $\mathrm{Cu}_{2} \mathrm{O}$ island and step edge "1" with time. $d$ suddenly increased at $\sim 31 \mathrm{~s}$, leading to the transition from step edge Cu to bulk Cu consumption. 
thickness difference between the $\mathrm{Cu}$ film and the $\mathrm{Cu}_{2} \mathrm{O}$ island, the amount of $\mathrm{Cu}$ lost from the surface steps is comparable to the amount of $\mathrm{Cu}$ added to $\mathrm{Cu}_{2} \mathrm{O}$. This indicates that $\mathrm{Cu}$ detaching from step edges is the source of $\mathrm{Cu}$ for $\mathrm{Cu}_{2} \mathrm{O}$ growth in the early oxidation stage. Later, the $\mathrm{Cu} \| \mathrm{Cu}_{2} \mathrm{O}$ interface migrates toward the $\mathrm{Cu}$ substrate, indicating that in later stage oxidation, the substrate serves as the $\mathrm{Cu}$ source. The transition between $\mathrm{Cu}$ sources is determined by the distance from the nearest step edge (Fig. 3d), which is explainable by $\mathrm{Cu}$ diffusion. When the oxide island is near a step edge, $\mathrm{Cu}$ detached from surface steps can easily diffuse to the oxide island via surface diffusion. However, when there are very few surface steps or the oxide island is far away from the surface steps, bulk $\mathrm{Cu}$ diffusion from the $\mathrm{Cu}$ substrate to the gas ||oxide interface becomes more efficient. As shown in Supplementary Note 8, even on reconstructed Cu surfaces, the diffusion barrier of $\mathrm{Cu}$ surface diffusion is still lower than that of bulk diffusion, leading to less-faceted oxide shapes during the interfacial $\mathrm{Cu}$ sourcing stage.

Mechanism of 3D $\mathrm{Cu}_{2} \mathrm{O}$ island growth. Based on the above discussion and the energetic data summarized in Supplementary Table 7, the mechanism of the unusual epitaxial oxide island growth processes during $\mathrm{Cu}$ oxidation, summarized in Fig. 4, is:

a. Due to surface reconstruction, $\mathrm{O}_{2}$ dissociation on the $\mathrm{Cu}$ surface is inhibited, so $\mathrm{O}$ adatoms are provided by $\mathrm{O}_{2}$ dissociative absorption on $\mathrm{Cu}_{2} \mathrm{O}$ surfaces ${ }^{2,46}$. The preferred diffusion barriers and adsorption energies of $\mathrm{O}$ on $\mathrm{Cu}_{2} \mathrm{O}$ (110) over those on $\mathrm{Cu}_{2} \mathrm{O}(100)$ suggest more diffusing $\mathrm{O}$ atoms will be present on the $\mathrm{Cu}_{2} \mathrm{O}(110)$ surface.

b. When there are $\mathrm{Cu}$ surface steps nearby, $\mathrm{Cu}$ adatoms detached from $\mathrm{Cu}$ step edges diffuse to $\mathrm{Cu}_{2} \mathrm{O}$ surfaces via surface diffusion. Because of the preferred diffusion barriers and adsorption energies of $\mathrm{Cu}$ on $\mathrm{Cu}_{2} \mathrm{O}(110)$, more $\mathrm{Cu}$ atoms will diffuse on $\mathrm{Cu}_{2} \mathrm{O}(110)$ than $\mathrm{Cu}_{2} \mathrm{O}(100)$. Due to the lower surface energy of $\mathrm{Cu}_{2} \mathrm{O}(110)$ and more favorable adsorption energies of $\mathrm{Cu}$ and $\mathrm{O}$ on the $\mathrm{Cu}_{2} \mathrm{O}(110)$ step, $\mathrm{Cu}_{2} \mathrm{O}$ nuclei will form on $\mathrm{Cu}_{2} \mathrm{O}(110)$. This is followed by the growth of $\mathrm{Cu}_{2} \mathrm{O}$ monolayers in an atomic adsorption process directed toward the growth front of the new layer. The vapor deposition process to grow oxides can be viewed as an extreme case of this scenario, where there are sufficient mobile $\mathrm{Cu}$ atoms present to directly react with $\mathrm{O}$ atoms ${ }^{45}$

c. The new $\mathrm{Cu}_{2} \mathrm{O}$ layer grows in this adatom growth method until the edge of the layer reaches the ridge of the previous $\mathrm{Cu}_{2} \mathrm{O}$ layer, then a new $\mathrm{Cu}_{2} \mathrm{O}$ layer nucleates following the steps in (a) and (b). This leads to the observed layer-bylayer growth along $\mathrm{Cu}_{2} \mathrm{O}(110)$. For each monolayer, the growth of a new $\mathrm{Cu}_{2} \mathrm{O}$ layer on the $\mathrm{Cu}_{2} \mathrm{O}(110)$ facet follows the diffusion-limited Frank-van der Merwe growth process with cubic growth rate $l^{3} \sim t$. However, due to the preference of $\mathrm{Cu}_{2} \mathrm{O}(110)$ over $\mathrm{Cu}_{2} \mathrm{O}(100)$ in both kinetics and energetics, the overall $\mathrm{Cu}_{2} \mathrm{O}$ island follows the Stranski-Krastanov growth model. When the $\mathrm{Cu}$ surface steps are far away, substrate $\mathrm{Cu}$ will feed $\mathrm{Cu}_{2} \mathrm{O}$ growth by interfacial diffusion via place exchange with $\mathrm{Cu}$ vacancies in $\mathrm{Cu}_{2} \mathrm{O}$ islands.

\section{Discussion}

Using DFT, we have investigated the energetics of several most probable diffusion paths, and corresponding thermodynamic states, that are proposed to underline studied experimental observations. However, a complete understanding of studied oxide growth dynamics is beyond the capabilities of DFT alone,

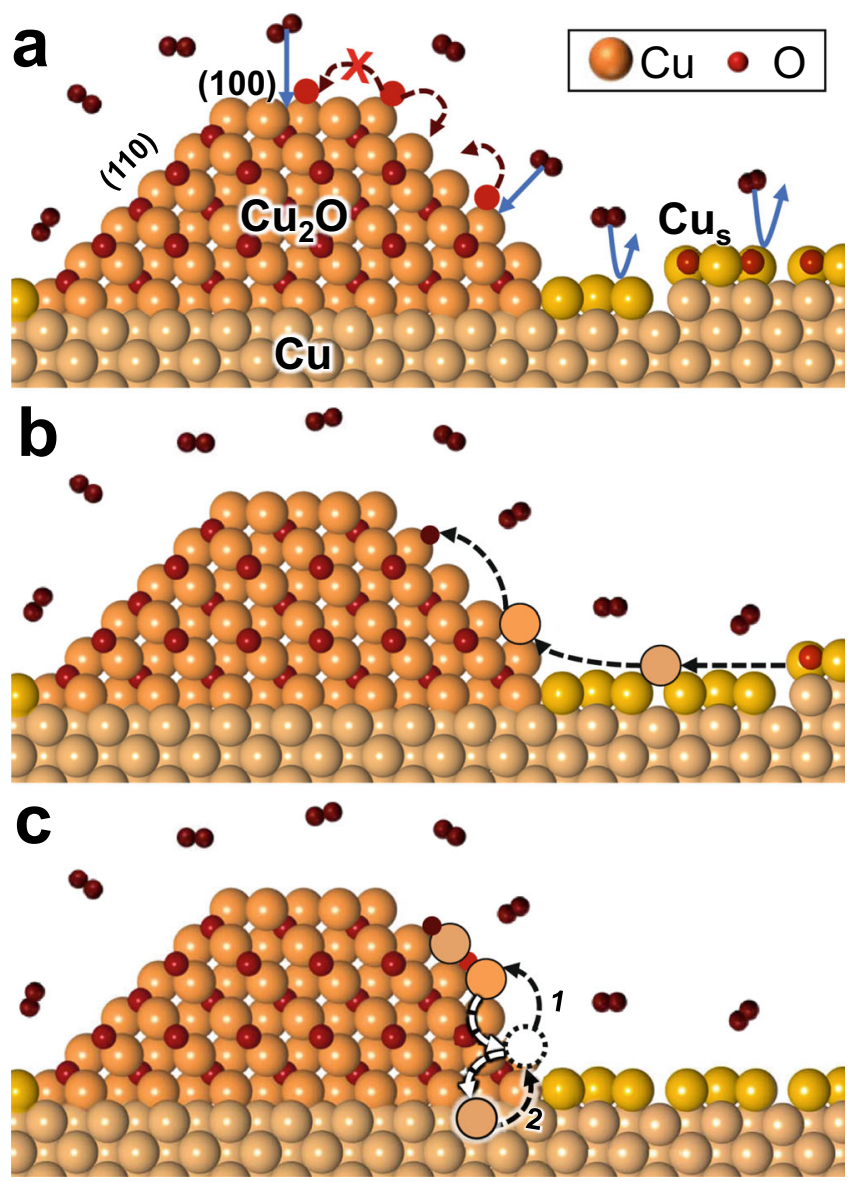

Fig. 4 Schematic of $\mathbf{C u}_{\mathbf{2}} \mathbf{O}$ growth mechanism. a Dissociative adsorption of $\mathrm{O}_{2}$ (red atoms) is blocked on the reconstructed $\mathrm{Cu}$ surface $\left(\mathrm{Cu}_{\mathrm{s}}\right.$, gold atoms) and performed on $\mathrm{Cu}_{2} \mathrm{O}$. Given lower diffusion barriers and favorable $\mathrm{O}$ adsorption energies on $\mathrm{Cu}_{2} \mathrm{O}(110)$, more $\mathrm{O}$ atoms segregate toward $\mathrm{Cu}_{2} \mathrm{O}(110)$. b When $\mathrm{Cu}$ steps are nearby, $\mathrm{Cu}$ adatoms detached from $\mathrm{Cu}$ step edges, diffuse to $\mathrm{Cu}_{2} \mathrm{O}$ islands, and attach to $\mathrm{O}$ atoms to form $\mathrm{Cu}_{2} \mathrm{O}$ monolayers, given favorable $\mathrm{Cu}$ and $\mathrm{O} E_{a d s}$ on $\mathrm{Cu}_{2} \mathrm{O}(110)$ steps. c When $\mathrm{Cu}$ surface steps are far away, substrate $\mathrm{Cu}$ will feed the growth of $\mathrm{Cu}_{2} \mathrm{O}$ via interface diffusion, namely through place exchange with $\mathrm{Cu}$ vacancies (dashed circle). $\mathrm{Cu}$ atoms from $\mathrm{Cu}_{2} \mathrm{O}$, the $\mathrm{Cu}$ surface, and the $\mathrm{Cu}$ bulk are colored orange, gold, and beige, respectively. $\mathrm{O}$ atoms are colored dark red.

especially when considering the many possible diffusion processes that induce concerted oxide nucleation and growth processes over multiple island layers. Comparisons between statistical conclusions and ETEM observations made in "Correlating Statistical Results with Experimental Observations" (Supplementary Note 4) demonstrate that limitations in $\mathrm{Cu}$ sourced from adjacent island layers contribute to observed island shapes and relative layer growth rates. Therefore, the combination of surface orientations and terminations predicted by simulation, island shape evolution by ETEM observations, and relative growth rates characterized by statistical conclusions, is needed to completely depict oxide growth dynamics.

Our results provide direct, atomic-scale growth dynamics of 3D epitaxial oxide island growth. Instead of multilayer growth along substrate surfaces to form wedding-cake shaped islands, we found the growth of 3D epitaxial oxide islands follows a layer-by-layer growth mechanism along a preferred facet. The growth kinetics of each oxide monolayer is consistent with predictions from the diffusion-limited 2D Frank-van der Merwe growth model for thin-films ${ }^{37}$. To our knowledge, this is the first atomic-resolution 
experimental proof of the atomic-level growth dynamics of 3D islands. Our study sheds new light on the epitaxial oxide growth mechanism and provides a deeper understanding of the dynamic processes involved in initial oxidation, which will ultimately help to precisely predict, design, and control nanostructured oxide growth. Our findings would apply to other metals-such as $\mathrm{Al}^{47}$, $\mathrm{Ni}-\mathrm{Cr}^{4,48}, \mathrm{Mo}^{30}, \mathrm{Mg}^{49,50}$ and $\mathrm{Ag}^{51}$ - where a similar layer-by-layer oxide growth was observed for the islands, though without confirmation on the early stages. Moreover, this work demonstrates that with meticulous in situ TEM experiments and advanced data analysis, statistically meaningful quantitative atomic-scale growth kinetics can be resolved. When complemented with correlated theoretical simulations, such work will promote the understanding of nanoscale dynamics to a new level.

\section{Methods}

Provided in Supplementary Information.

\section{Data availability}

All data is available in the main text or the Supplementary Materials (Supplementary Movies S1-S5, Methods, Supplementary Notes 1-8, Supplementary Notes 1-8, Supplementary Figs. 1-31, and Supplementary Tables 1-7).

\section{Code availability}

The code for in situ movie analysis and statistical analysis are available from the corresponding author on request.

Received: 3 August 2020; Accepted: 31 March 2021;

Published online: 13 May 2021

\section{References}

1. Hansen, P. L. Atom-resolved imaging of dynamic shape changes in supported copper nanocrystals. Science 295, 2053-2055 (2002).

2. Gattinoni, C. \& Michaelides, A. Atomistic details of oxide surfaces and surface oxidation: the example of copper and its oxides. Surf. Sci. Rep. 70, 424-447 (2015).

3. Luc W. et al. Two-dimensional copper nanosheets for electrochemical reduction of carbon monoxide to acetate. Nat. Catal. 2, 423-430 (2019).

4. Luo, L. et al. Atomic origins of water-vapour-promoted alloy oxidation. Nat. Mater. 17, 1-6 (2018).

5. Mortazavi, N. et al. Interplay of water and reactive elements in oxidation of alumina-forming alloys. Nat. Mater. 17, 610-617 (2018).

6. Sáenz-Trevizo, A. et al. Functional Nanostructured Oxides: Synthesis, Properties, and Applications (Elsevier Inc., 2018).

7. McKee, R. A., Walker, F. J. \& Chisholm, M. F. Physical structure and inversion charge at a semiconductor interface with a crystalline oxide. Science 293, 468-471 (2001).

8. Scully, J. R. The COVID-19 pandemic, part 1: can antimicrobial copper-based alloys help suppress infectious transmission of viruses originating from human contact with high-touch surfaces? CORROSION 76, 523-527 (2020).

9. Netzer, F. P. "Small and beautiful" - the novel structures and phases of nanooxides. Surf. Sci. 604, 485-489 (2010).

10. Cong, S., Tian, Y., Li, Q., Zhao, Z. \& Geng, F. Single-crystalline tungsten oxide quantum dots for fast pseudocapacitor and electrochromic applications. $A d v$. Mater. 26, 4260-4267 (2014).

11. Chu, Y. H. Van der Waals oxide heteroepitaxy.npj Quantum Mater. 2, 1-5 (2017).

12. Zhu, Q., Zou, L., Zhou, G., Saidi, W. A. \& Yang, J. C. Early and transient stages of $\mathrm{Cu}$ oxidation: atomistic insights from theoretical simulations and in situ experiments. Surf. Sci. 652, 98-113 (2016).

13. Basic Energy Sciences(BES) DoE. Basic Research Needs for Transformative Manufacturing (Brochure). (2020).

14. Barth, J. V., Costantini, G. \& Kern, K. Engineering atomic and molecular nanostructures at surfaces. Nature 437, 671-679 (2005).

15. Tersoff, J., Teichert, C. \& Lagally, M. G. Self-organization in growth of quantum dot superlattices. Phys. Rev. Lett. 76, 1675-1678 (1996).

16. Wagner, C. \& Hammen, H. Conductivity and oxygen excess in cuprous oxide. Z. f.ür. Physikalische Chem. 40, 197-206 (1938).

17. Cabrera, N. \& Mott, N. F. Theory of the oxidation of metals. Rep. Prog. Phys. 12, 308-308 (1949).
18. Franchy, R. Growth of thin, crystalline oxide, nitride and oxynitride films on metal and metal alloy surfaces. Surf. Sci. Rep. 38, 195-294 (2000).

19. Brune, H. Epitaxial Growth of Thin Films. Surface and Interface Science. (eds Wandelt, K.) https://doi.org/10.1002/9783527680566.ch20 (Wiley-VCH Verlag GmbH \& Co. KGaA, 2014).

20. Jesson, D. E., Chen, K. M. \& Pennycook, S. J. Kinetic pathways to strain relaxation in the Si-Ge system. MRS Bull. 21, 31-37 (1996).

21. Michely, T., Krug, J. \& Concepts, B. Layer-By-Layer Growth and Growth Manipulation (Springer, 2004).

22. Medeiros-Ribeiro, G., Bratkovski, A. M., Kamins, T. I., Ohlberg, D. A. A. \& Williams, R. S. Shape transition of germanium nanocrystals on a silicon (001) surface from pyramids to domes. Science 279, 353-355 (1998).

23. Ross, F. M., Tromp, R. M. \& Reuter, M. C. Transition states between pyramids and domes during Ge/Si island growth. Science 286, 1931-1934 (1999).

24. Mo, Y. W., Swartzentruber, B. S., Kariotis, R., Webb, M. B. \& Lagally, M. G. Growth and equilibrium structures in the epitaxy of $\mathrm{Si}$ on $\mathrm{Si}(001)$. Phys. Rev. Lett. 63, 2393-2396 (1989).

25. Shvets, I. V., Murphy, S. \& Kalinin, V. Nanowedge island formation on Mo(1 110$)$. Surf. Sci. 601, 3169-3178 (2007).

26. Lyubinetsky, I., Lea, A. S., Thevuthasan, S. \& Baer, D. R. Formation of epitaxial oxide nanodots on oxide substrate: $\mathrm{Cu}_{2} \mathrm{O}$ on $\mathrm{SrTiO}_{3}\left(\begin{array}{ll}1 & 0\end{array}\right)$. Surf. Sci. 589, 120-128 (2005).

27. Markworth, P. R. et al. Coherent island formation of $\mathrm{Cu} 2 \mathrm{O}$ films grown by chemical vapor deposition on $\mathrm{MgO}(110)$. J. Mater. Res. 16, 2408-2414 (2001).

28. Ottosson, M., Lu, J. \& Carlsson, J. O. Chemical vapour deposition of $\mathrm{Cu} 2 \mathrm{O}$ on $\mathrm{MgO}(100)$ from $\mathrm{CuI}$ and $\mathrm{N}_{2} \mathrm{O}$ : aspects of epitaxy. J. Cryst. Growth 151, 305-311 (1995).

29. Zhou, G. \& Yang, J. C. In-Situ Electron Microscopy: Applications in Physics, Chemistry and Materials Science. https://doi.org/10.1002/9783527652167.ch8 (Wiley-VCH Verlag GmbH \& Co. KGaA, 2012).

30. Yu J. et al. Atomic mechanism in layer-by-layer growth via surface reconstruction. Nano Lett. 19, 4205-4210 (2019).

31. Li, L. et al. Surface-step-induced oscillatory oxide growth. Phys. Rev. Lett. 113, $1-5$ (2014).

32. Yang, J. C. \& Zhou, G. In situ ultra-high vacuum transmission electron microscopy studies of the transient oxidation stage of $\mathrm{Cu}$ and $\mathrm{Cu}$ alloy thin films. Micron 43, 1195-1210 (2012).

33. Zhou, G. \& Yang, J. C. Initial oxidation kinetics of $\mathrm{Cu}(100)$, (110), and (111) thin films investigated by in situ ultra-high-vacuum transmission electron microscopy. J. Mater. Res. 20, 1684-1694 (2005).

34. Zhou, G. et al. In situ atomic-scale visualization of oxide islanding during oxidation of Cu surfaces. Chem. Commun. 49, 10862-10864 (2013).

35. Holloway, P. H. \& Hudson, J. B. Kinetics of the reaction of oxygen with clean nickel single crystal surfaces. Surf. Sci. 43, 123-140 (1974).

36. O'Reilly, M. et al. Investigation of the oxidation behaviour of thin film and bulk copper. Appl. Surf. Sci. 91, 152-156 (1995).

37. Bartelt, M. C. \& Evans, J. W. Scaling analysis of diffusion-mediated island growth in surface adsorption processes. Phys. Rev. B 46, 12675-12687 (1992).

38. Tang, L.-H. Island formation in submonolayer epitaxy. J. de. Phys. I 3, 935-950 (1993)

39. Evans, J. W., Thiel, P. A. \& Bartelt, M. C. Morphological evolution during epitaxial thin film growth: formation of 2D islands and 3D mounds. Surf. Sci. Rep. 61, 1-128 (2006).

40. Chow, G. C. Tests of equality between sets of coefficients in two linear regressions. Econometrica 28, 591-605 (1960).

41. Chi, H. et al. In situ environmental TEM observation of two-stage shrinking of $\mathrm{Cu} 2 \mathrm{O}$ islands on $\mathrm{Cu}(100)$ during methanol reduction. Phys. Chem. Chem. Phys. 22, 2738-2742 (2020).

42. Zhu, Q., Saidi, W. A. \& Yang, J. C. Enhanced mass transfer in the step edge induced oxidation on $\mathrm{Cu}(100)$ surface. J. Phys. Chem. C. 121, 11251-11260 (2017).

43. Zhu, Q., Saidi, W. A. \& Yang, J. C. Step-induced oxygen upward diffusion on stepped $\mathrm{Cu}(100)$ surface. J. Phys. Chem. C. 119, 251-261 (2015).

44. Zhu, Q., Saidi, W. A. \& Yang, J. C. Step-edge directed metal oxidation. J. Phys. Chem. Lett. 7, 2530-2536 (2016).

45. Zhou, G. et al. Step-edge-induced oxide growth during the oxidation of $\mathrm{Cu}$ surfaces. Phys. Rev. Lett. 109, 1-5 (2012).

46. Yu, X., Zhang, X., Tian, X., Wang, S. \& Feng, G. Density functional theory calculations on oxygen adsorption on the $\mathrm{Cu}_{2} \mathrm{O}$ surfaces. Appl. Surf. Sci. 324, 53-60 (2015)

47. Oh, S. H. et al. Oscillatory mass transport in vapor-liquid-solid growth of sapphire nanowires. Science 330, 489-493 (2010).

48. Luo, L. et al. In situ atomic scale visualization of surface kinetics driven dynamics of oxide growth on a Ni-Cr surface. Chem. Commun. 52, 3300-3303 (2016).

49. Zheng, H. et al. Direct atomic-scale observation of layer-by-layer oxide growth during magnesium oxidation. Appl. Phys. Lett. 104, 141906-141906 (2014).

50. Cao, F. et al. Atomistic observation of structural evolution during magnesium oxide growth. J. Phys. Chem. C. 120, 26873-26878 (2016). 
51. Zhu, Q. et al. Defect-driven selective metal oxidation at atomic scale. Nat. Commun. 12, 6-13 (2021).

\section{Acknowledgements}

We acknowledge Mr. Xianhu Sun (SUNY Binghamton), Drs. Hao Chi and Henry Ayoola (University of Pittsburgh) for helpful discussions and assistance in experiments. The experimental work was performed at the Petersen Institute of NanoScience and Engineering (PINSE) Nanoscale Fabrication and Characterization Facility (NFCF) at University of Pittsburgh. We thank NFCF staff Mr. Matt France and Dr. Susheng Tan for their assistance. This research used resources of the Environmental TEM Catalysis Consortium (ECC), which is supported by the University of Pittsburgh and Hitachi High Technologies. Computational resources were provided by the University of Pittsburgh Center for Research Computing (CRC), the Extreme Science and Engineering Discovery Environment (XSEDE) supported by the National Science Foundation (NSF OCI1053575), and at the Argonne Leadership Computing Facility, which is a DOE Office of Science User Facility supported under Contract DE-AC02-06CH11357.

\section{Author contributions}

J.C.Y. and W.A.S. conceived and directed the project. M.L. conducted the experiments, data analysis, and drafted the manuscript. M.T.C. conducted D.F.T. simulations and statistical analysis. M.A.G. and S.D.H. assisted with the data analysis. All authors contributed to results discussion and manuscript refinement.

\section{Funding}

This work is supported by the National Science Foundation (NSF DMR-1410055, NSF DMR-1508417, and NSF CMMI-1905647).

\section{Competing interests}

The authors declare no competing interests.

\section{Additional information}

Supplementary information The online version contains supplementary material available at https://doi.org/10.1038/s41467-021-23043-w.

Correspondence and requests for materials should be addressed to W.A.S. or J.C.Y.

Peer review information Nature Communications thanks Nicholas Harrison, Igor Shvets, and the other, anonymous, reviewer(s) for their contribution to the peer review of this work. Peer reviewer reports are available.

Reprints and permission information is available at http://www.nature.com/reprints

Publisher's note Springer Nature remains neutral with regard to jurisdictional claims in published maps and institutional affiliations.

\begin{abstract}
(c) (i)
Open Access This article is licensed under a Creative Commons Attribution 4.0 International License, which permits use, sharing, adaptation, distribution and reproduction in any medium or format, as long as you give appropriate credit to the original author(s) and the source, provide a link to the Creative Commons license, and indicate if changes were made. The images or other third party material in this article are included in the article's Creative Commons license, unless indicated otherwise in a credit line to the material. If material is not included in the article's Creative Commons license and your intended use is not permitted by statutory regulation or exceeds the permitted use, you will need to obtain permission directly from the copyright holder. To view a copy of this license, visit http://creativecommons.org/ licenses/by/4.0/.
\end{abstract}

(C) The Author(s) 2021 